\title{
Sharing Genes Fosters Identity Fusion and Altruism
}

\author{
Alexandra Vázquez \\ Ángel Gómez \\ Juan R. Ordoñana \\ William B. Swann \\ Harvey Whitehouse
}

\begin{abstract}
Author Note:
Correspondence concerning this paper should be addressed to Alexandra Vázquez.

Universidad Nacional de Educación a Distancia. Departamento de Psicología Social y de las Organizaciones. C/Juan del Rosal, 10, 28040 Madrid (Spain). Telephone: 34 913988918. Email: alx.vazquez@psi.uned.es
\end{abstract}

Acknowledgement:

This work was supported by the Spanish Ministry of Economy under Grant PSI201567754-P; the Spanish Ministry of Science and Innovation under Grant PSI2014-56680R; the Séneca Foundation under Grant 19479/PI/14; the National Science Foundation under Grant BCS 1528851; and the UK's Economic and Social Research Council under Grant RES-060-25-0085. 


\begin{abstract}
Researchers have shown that the more genes twins share, the more they care about one another. Here we examine a psychological mediator of such genetic influences, "identity fusion" (a visceral sense of oneness with them). Results supported this hypothesis. Relative to dizygotic twins, monozygotic twins reported stronger fusion and elevated desire to have contact and share experiences with their twin (Study 1), to forgive and grant favors to their twin after being disappointed by him/her (Study 2), and willingness to make sacrifices for their twin (Study 3). Fusion with the twin mediated the impact of zygosity on these outcomes. These findings demonstrate that genetic relatedness fosters a powerful feeling of union with one's twin that predicts sharing, tolerance and self-sacrificial behavior toward him or her.
\end{abstract}




\section{Sharing Genes Fosters Identity Fusion and Altruism}

Twins who share all of their genes (monozygotic or MZ twins) maintain closer contact and cooperate more than twins who share half of their genes (dizygotic or DZ twins). Nevertheless, little is known about the proximate psychological mechanisms that underlie the special bond between identical twins. In this report we test the idea that identity fusion, a visceral sense of oneness with another entity, may help explain the strong attachment that identical twins have to one another. Specifically, in three studies we test the hypothesis that degree of fusion between twins mediates the impact of zygosity on several manifestations of closeness with the twin, including desire for contact, tolerance and self-sacrificial behavior. This is the first attempt to examine how identity fusion varies as a function of zygosity and how the feeling of oneness with the twin affects twin relationships.

\section{Identity Fusion among Twins}

The bonds that MZ twins form toward one another are remarkably intense (Neyer, 2002). Relative to DZs, MZs report more: intimate relationships (Segal, 2000); time spent together (Rose, 2002); frequent contact and propinquity (Rose, Kaprio, Williams, Viken, \& Obremski, 1990); mutual support and cooperation (Neyer, 2002; Segal \& Hershberger, 1999), mutual trust (McGuire, Segal, Gill, Whitlow, \& Clausen, 2010); and grieving following the loss of the twin (Segal \& Ream, 1998). Although the intensity of MZ bonds is beyond question, the psychological mechanism that gives rise to these bonds is not. We propose that the identity fusion formulation (Gómez \& Vázquez, 2015; Swann \& Buhrmester, 2015) may be useful here.

Researchers developed identity fusion theory to explain the extreme behaviors that people sometimes enact for their group (Swann, Jetten, Gómez, Whitehouse, \& Bastian, 2012). They defined identity fusion as a visceral feeling of oneness with a 
group that occurs when the boundaries between personal identity and the group are permeable. Feelings of fusion are associated with a sense of oneness with the group and the perception that the group and the self reciprocally strengthen one another (Gómez, Brooks, et al., 2011). Identity fusion predicts willingness to fight and die for fellow group members (Gómez, Brooks, et al. 2011; Swann, Gómez, Seyle, Huici, \& Morales, 2009), self-sacrifice to save group members who are imperiled in moral dilemmas (Swann, Burhmester, et al., 2014; Swann, Gómez, et al., 2014), and donating blood for fellow group members (Buhrmester, Fraser, Lanman, Whitehouse, \& Swann, 2014). In addition, those persons who were more fused with their battalion were also more likely to engage in front line combat in the 2011 Libyan revolution (Whitehouse, McQuinn, Buhrmester, \& Swann, 2014) and transsexuals who were more fused with their desired sex were more likely to undergo sex-reassignment surgery (Swann et al., 2015).

Although most past research has focused on large, extended groups, fusion is a particularly powerful moderator of behavior toward small, family like groups (Whitehouse et al., 2014) and dyads (Vázquez, Gómez, Ordoñana, \& Paredes, 2015). Indeed, when asked to specify the group for which they would be most willing to die, people from all over the world overwhelmingly nominated a small group — family (Swann, Buhrmester, et al., 2014).

Fusion with small groups may be a particularly strong predictor of pro-group behavior because perception of shared core characteristics (e.g., genes) tends to be high in such groups. For example, encouraging fused persons to focus on shared core characteristics of members of their country (genes or values) increased their endorsement of making extreme sacrifices for their country (Swann, Buhrmester, et al., 2014). One marker of shared genes is appearance (DeBruine, 2002). For example, through a process known as "phenotypic matching", MZ twins may note the nearly 
identical appearance of their twin and experience a strong perception of physical oneness. This perception of oneness may, in turn, foster feelings of fusion, tolerance and willingness to make sacrifices for the twin.

Shared life experiences may also promote fusion among MZ twins. That is, based on the appearance of MZ twins, other people may develop similar expectations about them and hence treat them more uniformly than they treat DZ twins (Scarr \& Carter-Saltzman, 1979). As a consequence, MZ twins will share more experiences with one another than DZs (Joseph, 2013) and these shared experiences may foster the perception of oneness associated with fusion (Jong, Whitehouse, Kavanagh, \& Lane, 2015; Whitehouse \& Lanman, 2014).

Identity fusion with the twin is related but different from other measures of interpersonal closeness. For instance, self-expansion theory (Aron \& Aron, 1996; Aron, Aron, \& Smollan, 1992) states that people use close relationships to self-expand by including others in the self. The inclusion of others in the self increases one's material resources, social networks, identities and perspectives, much as aggressor companies in hostile takeovers acquire the resources of the company they have acquired. In contrast, identity fusion involves sharing rather than appropriating qualities of the other person or group. Moreover, identity fusion involves an irrevocable devotion to the group or its members (i.e., Gómez, Morales, Hart, Vázquez, \& Swann, 2011) that is absent from the self-expansion model. Alignment with the other not only makes strongly fused individuals feel stronger, it also compels them to strengthen the group through their actions, including extraordinary actions.

\section{Consequences of Fusion with One's Twin}

The relatively high levels of fusion experienced by MZ twins should influence several behaviors. For example, fusion should predispose people to have more contact 
with the twin (see Neyer, 2002). In addition, strongly fused participants should be more inclined to "coexperience" activities and various social outcomes.

Fusion should also influence how people react to a disappointment caused by the twin. That is, although previous research on identity fusion has not examined reactions to disappointment per se, fused individuals did remain loyal to their group even after some of its members have excluded them (Gómez, Morales et al., 2011). Given that exclusion from the group is surely disappointing, this finding suggests that fusion will encourage people to forgive disappointing behavior on the part of the twin.

Moreover, based on evidence that fusion predicts willingness to sacrifice oneself for the group (Swann \& Buhrmester, 2015), we expect that individuals who are strongly fused with their twin will be more willing to make sacrifices for the twin. We tested these hypotheses in three studies conducted with pairs of MZ and DZ twins.

One final question is whether the gender of DZ participants (same vs. different) will make a difference. Previous research exploring the personal relationships between DZs of different and same gender shows mixed results. Relative to different-gender DZs, same-gender DZs have been found to share more friends with their twin (Thorpe \& Gardner, 2006), but to have a less favorable image of him/her (Danby \& Thorpe, 2006) and higher levels of conflict and rivalry (Fortuna, Goldner, \& Knafo, 2010). At first sight, one would expect that the higher physical similarity of same-gender DZs would increase fusion and its correlates as compared with DZs differing in gender. However, social expectations and parental treatment (e.g., more comparisons among twins the more alike they are) might promote stronger competitiveness among DZs of same gender as compared to DZs of different gender, which ultimately would reduce fusion. Insofar as these opposing forces neutralize each other, differences due to the gender of DZs may fail to materialize. 


\section{Study 1: Zygosity, Identity Fusion, and Desire for Contact/ Coexperience}

Study 1 tested whether zygosity would influence fusion with the twin and, in turn, desire for contact and coexperience with him/her. We expected that relative to DZs, MZs would display higher fusion with the twin and desire for contact and coexperience. Moreover, we anticipated that fusion with the twin would mediate the relationship between zygosity and the outcome variables.

\section{Method}

Participants. Trained personnel recruited participants on the telephone from the Murcia Twin Registry (MTR) (Ordoñana et al., 2013). The MTR is a population-based registry of adult multiples in a region of Spain, Murcia. The MTR collects information from the twins periodically to examine the relative contribution of genetic and environmental factors to the development of complex phenotypes, focusing on health and health-related behaviors. Participation in the MTR is voluntary, subjected to informed consent, and not remunerated. Twin zygosity is ascertained by a 12 -item questionnaire, which corresponds well with zygosity as determined by DNA testing with an agreement in nearly $96 \%$ of the cases (Ordoñana et al., 2013). Besides the measures reported, participants answered additional demographic and health-related questions that are not included here. More detailed information about recruitment procedures and data collection is provided elsewhere (Ordoñana et al., 2013).

Because there was no precedent for examining the impact of zygosity on fusion scores, it was difficult to estimate effects sizes. To err on the side of caution, we recruited a larger sample for Study 2, which includes two predictor variables, and considerably smaller samples for the remaining studies. The samples of the three studies were different. We deleted a total of 130 participants (Study 1: $N=30 ;$ Study 2: $N=60$; Study $3: N=40 ; M_{\mathrm{age}}=57.51, S D=7.23 ; 51.5 \%$ women) because their twin did not 
participate in the study. Note also that the degrees of freedom associated with the analyses vary slightly because participants occasionally failed to complete all measures.

One hundred and ninety twins $(50.5 \%$ females, mean age $=55.69, S D=6.24)$ participated in Study 1. Table 1 shows the sample distributions of all studies according to Gender and Zygosity.

[Table 1 about here]

Procedure. Participants learned that they would be participating in a study of health that included several questions unrelated to this study. To avoid participant fatigue, we included short scales in all studies.

Identity fusion with the twin was measured by an adapted version of the fusion scale developed by Gómez, Brooks, et al. (2011), consisting of three items (e.g., "I am one with my twin") ranging from 0 (completely disagree) to 10 (completely agree), $\alpha=$ .70 (.69 and .76 for Study 2 and 3, respectively).

Desired contact with the twin was assessed by a three-item scale developed for this study (e.g., "How often do you visit your twin?") ranging from 0 (never) to 6 (several times per day), $\alpha=.71$.

Desire for coexperience was evaluated by a three-item scale developed for this study (e.g., "I would prefer for me and my twin to perform the same on tasks and tests") ranging from 0 (completely disagree) to 10 (completely agree), $\alpha=.70$.

\section{Results}

Analytic strategy. Regression analyses were used based on the sandwich or Huber-White variance estimator (Gould \& Scribney, 1999), which adjusts estimated standard errors to account for data dependence between twins in a pair and provides statistical tests that are robust to model assumptions. STATA 12.0 was used to conduct 
those analyses. All significance tests were two tailed. We were particularly interested in two comparisons: (a) MZs vs. Dzs, and (b) same-gender DZs vs. different-gender DZs. To make these comparisons, we used an orthogonal coding method, the Helmert Contrast (West, Aiken, \& Krull, 1996). For the first comparison we created a new variable named D1 and coded as -2/3 (MZs), 1/3 (same-gender DZs) and 1/3 (differentgender DZs). For the second comparison we created a new variable named D2 and coded as 0 (MZs), - 1/2 (same-gender DZs) and 1/2 (different-gender DZs). Both variables were entered simultaneously in the regression analyses.

Overview. Table 2 shows descriptive statistics and correlations. Since gender (1 female, 1 male) and D1 are dichotomous, the correlations involving these two variables are point-biserial. D1, D2 and fusion correlated significantly with desire for contact and coexperience. However, fusion was correlated more strongly with the outcome measures than D1 and D2. Desire for contact and coexperience were positively correlated.

[Table 2 about here]

Fusion with the twin. Prior to analyzing the effect of fusion on our outcome variables, we regressed the control -age and gender of the participant (-1 female, 1 male)- and zygosity variables (D1 and D2) on fusion with the twin. The effect of D1 (MZs vs. DZs) was significant, $B=-1.00$, Wald $\chi^{2}(1)=9.26, p=.002$, indicating stronger fusion in MZs than in DZs, $M=7.97, S D=1.73$ vs. $M=7.01, S D=2.33$. The effect of D2 (same-gender vs. different gender DZs) was also significant, $B=-1.56$, Wald $\chi^{2}(1)=12.80, p<.001$, indicating stronger fusion in same-gender DZs than in different-gender DZs, $M=7.76, S D=1.94$ vs. $M=6.19, S D=2.45$. The effect of gender was also significant, $B=0.28$, Wald $\chi^{2}(1)=4.16, p=.04$, indicating a slight 
tendency of males to feel stronger fusion than females, $M=7.02, S D=2.33$ vs. $M=$ $7.57, S D=2.04$

Desire for contact with and coexperience with the twin We conducted two hierarchical regression analyses on desire for contact and coexperience with the twin respectively. In the first step (Model 1) we entered the control-gender and age- and zygosity variables (D1 and D2). In the second step (Model 2) we added fusion with the sibling to the model.

In the regression on desire for contact with the twin the value of $R^{2}$ of Model 2 significantly increased as compared to Model 1. As shown in Table 3, the effect of D1 was significant in Model 1. MZs reported having more desire for contact with their twin than DZs, $t(180)=2.59, p=.01, M \mathrm{~s}=4.10$ and $3.51, S D \mathrm{~s}=1.42$ and 1.42 , respectively. The effect of D2 was also significant in Model 1, indicating that same-gender DZs expressed a stronger desire to have contact with their twin than different-gender DZs, $t(124)=3.98, p<.001, M \mathrm{~s}=3.95$ and $3.00, S D \mathrm{~s}=1.22$ and 1.46 , respectively. However, when identity fusion was included in Model 2 the effects of D1 and D2 reduced and identity fusion was the strongest predictor of desire for contact with the twin.

[Table 3 about here]

In the regression on coexperience the value of $R^{2}$ of Model 2 significantly increased as compared to Model 1. As shown in Table 3, the effects of D1 and D2 were only significant in Model 1, indicating that MZs expressed a stronger desire for coexperience than DZs, $t(188)=2.06, p=.04, M \mathrm{~s}=7.49$ and $6.73, S D \mathrm{~s}=1.86$ and 2.48 , respectively, and that same-gender DZs expressed a stronger desire for coexperience than different-gender DZs, $t(132)=2.26, p=.02, M \mathrm{~s}=7.19$ and $6.23, S D \mathrm{~s}=2.18$ and 2.70. However, in Model 2 the only significant effect was the effect of fusion. 
Mediational analyses. To test our hypotheses that fusion with the twin would mediate the effect of zygosity on our outcome variables, we conducted two bootstrapping tests ( $\mathrm{n}$ boots $=5,000)$ using Model 4 of PROCESS (Hayes, 2013) on desire for contact with the twin and desire for coexperience. The two Helmert contrasts were the predictors. Fusion with the twin was included as a mediator (centered) and age and gender as covariables. The analysis (see Figure 1) on desire for contact showed that the indirect effect via fusion was significant for both contrasts: Indirect effect (IE) for $\mathrm{D} 1=-0.26,95 \% C I=-0.4566$ to -0.1075 , and $\mathrm{IE}$ for $\mathrm{D} 2=-0.38,95 \% C I=-0.6742$ to 0.1682 .

[Figure 1 about here]

The analysis (see Figure 2) on desire for coexperience showed that the indirect effect via fusion was significant for both contrasts: Indirect effect (IE) for D1 $=-0.64$, $95 \% C I=-1.0616$ to -0.2832 , and IE for D2 $=-1.00,95 \% C I=-1.5994$ to -0.5284 .

[Figure 2 about here]

\section{Discussion}

Study 1 showed that relative to DZs, MZs displayed higher levels of fusion, desire for contact and coexperience with the twin. Furthermore, identity fusion fully mediated the effects of zygosity variables on the outcome measures. Unexpectedly, same-gender DZs pairs showed higher levels of fusion, desire for contact and coexperience with the twin than different-gender DZs. We will determine if this finding replicates in Study 2. In addition, Study 2 tested whether the pattern of results obtained in Study 1 would emerge with a different outcome measure, participants' reactions to being disappointed by their twin.

Study 2: Zygosity, Fusion, and Reactions to Disappointment 
In Study 2 we examined the link between zygosity, identity fusion and reactions to disappointment. As in Study 1, we expected that MZs would be more fused with their twin than DZs. We predicted also that readiness to forgive the twin would depend on the interaction between zygosity and previous disappointments. Finally, we expected that the effect of zygosity on forgiving would be mediated by feelings of fusion.

\section{Method}

Participants. Four hundred and eighty two participants (53.1\% females, mean age $=55.78, \mathrm{SD}=6.76$ ) were drawn from the population-based Murcia Twin Registry

Procedure. The procedure was similar to Study 1, with the major change being the shift to a new outcome measure. To assess disappointment with the twin, we asked participants whether they had ever felt disappointed because his/her twin did not defend him/her when someone criticized him/her or was not willing to do him/her a favor. Participants answered Yes or No to this question. Participants then indicated the extent to which they would be willing to (a) give their twin another chance and trust him/her again or (b) grant their twin whatever favor that he/she asked. The scale ranged from 0 (not willing at all) to 10 (completely willing). Since the correlation between these last items was modest, $r(462)=.58$, we conducted separate analyses.

\section{Results}

Overview. As in Study 1, we used Helmert contrasts to check whether there were differences between MZs and DZs on the one hand, and among same and different-gender DZs on the other hand. Table 4 shows that D1 (the first contrast comparing MZs to DZs) and fusion correlated significantly with reactions to disappointment. However, D2 (comparing DZs of different and same gender) did not correlate with any of the dependent variables. Fusion was a stronger predictor of reactions than zygosity. 
[Table 4 about here]

Fusion with the twin. Prior to analyzing the effect of fusion on our outcome variables, we regressed the control-age and gender (-1 female, 1 male)- and zygosity variables (D1 and D2) on fusion with the twin. The only significant effect was the effect of D1, $B=-1.23$, Wald $\chi^{2}(1)=29.52, p<.001$, indicating stronger fusion in MZs than in DZs, $M=7.88, S D=1.93$ vs. $M=6.68, S D=2.10$. No other effects were significant, $p s>.41$.

Willingness to trust the twin again. We conducted a regression on willingness to trust the twin again to determine how zygosity variables, previous disappointment and fusion affect this variable. As in Study 1, in the first step (Model 1) we entered the control (age and gender) and zygosity variables (D1 and D2). In the second step (Model 2) we added previous disspointment and the interaction between previous disappointment and zygosity variables. In the third step (Model 3) we included fusion with the twin. As Table 5 shows that the value of $R^{2}$ of Model 2 significantly increased as compared to Model 1, and the value of $R^{2}$ of Model 3 significantly increased as compared to Model 2. In model 1 the effects of D1 and gender were significant, indicating that MZs were more willing to trust their twin again than DZs, $M \mathrm{~s}=9.66$ and 9.31, $S D \mathrm{~s}=0.84$ and 1.61 , and that females were more willing to trust their twin again than males, $M=9.61, S D=1.21$ vs. $M=9.25, S D=1.50$. In Model 2, a main effect of dissapointment emerged indicating that twins that had not been disappointed were more willing to trust their twin than those who did report a disappointment, $M \mathrm{~s}=9.65$ and $8.97, S D s=0.93$ and 2.00 , respectively. This main effect was qualified by the interactive effect between D1 and disappointment, indicating that zygosity affects willingness to trust the twin when there has been a previous dissapointment, $B=-0.84$, $t(454)=-3.58, p<.001$, but not when no previous dissapointment has been reported, $B=$ 
$-0.14, t(454)=-0.94, p=.35$. That is, DZs are less inclined to trust their twin if they had been previously dissapointed by him/her as compared to MZs, $M=8.63$, $S D=2.36$ vs. $M=9.59, S D=1.07$. However, no differences between DZs and MZs emerged when no previous dissapointment had been reported, $M=9.47, S D=1.15$ vs. $M=9.73, S D=$ 0.66. In Model 3 the effect of D1 became non significant after including fusion. The effects of previous disappointment remained significant in Model 3, whereas the interactive effect became marginal. The effect of fusion was significant.

[Table 5 about here]

Willingness to do a favor We conducted a similar regression on willingness to do a favor. As Table 6 shows, the value of $R^{2}$ of Model 2 significantly increased as compared to Model 1, and the value of $R^{2}$ of Model 3 significantly increased as compared to Model 2. In model 1 the effect of D1 was significant, indicating that willingness to do the twin a favor was greater among MZs than DZs, Ms $=9.56$ and 9.26, $S D \mathrm{~s}=1.06$ and 1.51

In Model 2, a main effect of dissapointment emerged indicating that twins that had not been disappointed were more willing to do their twin a favor than those who did report a disappointment, $M \mathrm{~s}=9.55$ and $9.02, S D \mathrm{~s}=1.10$ and 1.84 . The effect of the interaction between D1 and disappointment did not reach significance. However, zygosity affected the willingness to do the twin a favor when there has been a previous disappointment, $B=-0.60, t(469)=-2.43, p=.02$, but not when no previous disappointment has been reported, $B=-0.18, t(469)=-1.24, p=.22$. That is, DZ twins are less inclined to do a favor if he/she had previously disappointed him/her twin as compared to MZ twins, $M=8.79, S D=2.16$ vs. $M=9.37, S D=1.15$. However, no differences between DZs and MZs emerged when no previous disappointment had been reported, $M=9.45, S D=1.15$ vs. $M=9.63, S D=1.02$. 
In Model 3 the effect of D1 became marginally significant, wheras the effect of fusion was significant.

[Table 6 about here]

Mediational analyses. To test our hypotheses that fusion with the twin would mediate the effect of zygosity on our outcome variables, we conducted two bootstrapping tests ( $\mathrm{n}$ boots $=5,000)$ using Model 5 of PROCESS (Hayes, 2013) on willingness to trust the twin again and willingness to do the twin a favor. As in Study 1, the two Helmert contrasts were included as predictors, although the second contrast yielded no significant effects on the outcome variables. Fusion with the twin was considered as a mediator (centered). Gender, age, previous disappointment and its interactions with Herlmert contrasts were entered as covariables. The analyses (see Figures 3 and 4) showed that the effects of D1 on our outcome variables were mediated by identity fusion, $I E=-0.18,95 \% C I=-0.3072$ to -0.0878 , for willingness to trust the twin again, and $I E=-0.21,95 \% C I=-0.3440$ to -0.1198 for willingness to do the twin a favor. Regarding D2, neither the total, nor the indirect and direct effects were significant (none of the confidence intervals contained 0 ).

[Figures 3 and 4 about here]

\section{Discussion}

This second study indicated that relative to DZs, MZs displayed higher identity fusion and more willingness to trust the again and do him/her a favor interactively with past disappointment. MZ twins were more willing than DZs to trust their twin and help him/her again if they had been previously disappointed by him/her. When no past offenses were reported, MZs and DZs reacted similarly. Among DZs, within-pair gender had no effect on fusion with twin. 
As in Study 1 fusion mediated the effect of zygosity on the outcome variables and explained most of the variance. In the last study we explored whether the differences between MZs and DZs also entails a priorization of the twin over other relatives.

\section{Study 3: Zygosity, Fusion, and Willingness to Engage in Pro-Twin Behavior}

Study 3 explored the relationship between zygosity, fusion and willingness to engage in pro-twin behavior. We predicted that MZs would express more willingness to do for their twin than for their parents and children, and that this effect would be mediated by identity fusion.

\section{Method}

Participants. Two hundred and twenty six participants (49.1\% females, mean age $=55.30, \mathrm{SD}=6.37$ ) were drawn from the population-based Murcia Twin Registry

Procedure. We used the same procedure as in previous studies. To evaluate the willingness to prioritize the twin over other relatives, we asked participants who had living parents and children to indicate (a) to what extent they would do for their twin more than they would do for their parents and (b) to what extent they would do for their twin more than they would do for their children. Responses to these two items ranged from 0 (completely disagree) to 10 (completely agree), $r(163)=.56$.

\section{Results}

Overview. As in previous studies, we used Helmert contrasts to compared MZs vs. DZs (D1) and same-gender DZs vs . different-gender DZs (D2). Table 7 shows that D1 and fusion correlated significantly with willingness to prioritize the twin over parents and children. However, the correlations of fusion were higher than the correlations of zygosity. Willingness to prioritize the twin over the parents and over 
one's children were also positively correlated. The correlations of D2 were not significant.

[Table 7 about here]

Table 7 shows the descriptive statistics. Lower scores on the priorization items indicate that participants did not agree to do more for their twin than for other relatives, whereas higher scores indicate that participants would do more for their twin than for other relatives. The mean score of the item regarding the prioritization of the twin over one's children is below the midpoint of the scale, $t(205)=-27.27, p<.001$, suggesting low agreement with the idea of giving priority to one's twin over one's children.

We conducted two hierarchical regression analyses on prioritizing the twin over parents and children. In the first step (Model 1) we entered the control (age and gender) and zygosity variables (D1 and D2). In the second step (Model 2) we added fusion with the twin to the model.

Fusion with the twin. Prior to analyzing the effect of fusion on our outcome variables, we regressed the control and zygosity variables on fusion with the twin. The only significant effect was the effect of D1, $B=-1.03$, Wald $\chi^{2}(1)=8.74, p=.003$, indicating stronger fusion in MZs than in DZs, $M=7.55, S D=2.14$ vs. $M=6.60, S D=$ 2.42. No other effects were significant, $p s>.25$.

Willingness to prioritize the twin over one's parents. In the regression on willingness to prioritize the twin over one's parents the value of $R^{2}$ of Model 2 significantly increased as compared to Model 1. As shown in Table 8, the only significant effect was the effect of D1, indicating that relative to DZs, MZs expressed more willingness to do for their twin than for their parents, $M \mathrm{~s}=6.00$ and 5.01, $S D \mathrm{~s}=$ 2.87 and 2.53, respectively. However, in Model 2 there was only a significant effect of fusion. 
[Table 8 about here]

Willingness to prioritize the twin over one's children. In the regression on willingness to prioritize the twin over one's children the value of $R^{2}$ of Model 2 significantly increased as compared to Model 1. As shown in Table 8, Model 1 only yielded a significant effect of D1, indicating that MZs expressed higher willingness to do more for their twin than for their children as compared to DZs, $M \mathrm{~s}=3.86$ and 2.97, $S D s=2.93$ and 2.55, respectively. However, in Model 2 there was only a significant effect of fusion.

Mediational analyses. To test our hypotheses that fusion with the twin would mediate the willingness to do for the twin more than for parents and for one's children we conducted two bootstrapping tests $(\mathrm{n}$ boots $=5,000$ ) using Model 4 of PROCESS (Hayes, 2013). The two Helmert contrasts were entered as predictors although the second contrast (D2) had no effect on the outcome variables. Fusion was considered as the mediator. Gender and age were included as covariables. The mediational analyses (see Figures 5 and 6) showed that the indirect effects of D1 via identity fusion were significant: $-0.56,95 \% C I=-1.0553$ to -0.1129 for parents, and $-0.42,95 \% C I=-$ 0.7491 to -0.1451 for children. The indirect effects of D2 were not significant (none of the confidence intervals contained zero).

[Figures 5 and 6 about here]

\section{Discussion}

Consistent with studies 1-2, fusion and willingness to sacrifice for one's twin was higher in MZs than in DZs. Once again fusion mediated the effects of zygosity and explained most of the variance found in our outcome variables. Similarity of gender among DZs produced no effects. 
To check whether there were differences in fusion among MZs and DZs of different and same gender, we collapsed data from the three studies. An ANOVA on identity fusion with gender and age as covariables yielded a significant effect of group, $F(1,893)=28.92, p<.001, \eta^{2}=.06$. Bonferroni tests indicated that MZs, $M=7.81, S D$ $=1.96$, felt significantly stronger fusion with their twin than same-gender and differentgender DZs, $M \mathrm{~s}=6.86$ and 6.58, SDs $=2.24$ and 2.23, $p \mathrm{~s}<.001$. However, the difference in fusion between same-gender and different-gender DZs was not significant, $p=.28$.

\section{General Discussion}

Our research helps explain how evolutionary principles and psychological mechanisms combine to explain prosociality among kin. To that end, we explored for the first time the influence of identity fusion on twin relationships. Consistent with evolutionary theory (Hamilton, 1964), zygosity exerted a strong influence on selfreported behaviors and behavioral intentions towards the twin across three studies. Relative to DZ twins, MZs expressed more desire for contact and coexperience with their twin and a stronger willingness to forgive him/her after being disappointed, and to do for him/her more than for their parents and children.

More importantly, these findings identify one of the psychological mechanisms by which genetic relatedness affects willingness to act on behalf of one's twin. Fusion with the twin mediated the relationship between zygosity and prosocial behavioral intentions. MZs were more fused with their twin than DZs and their stronger feelings of fusion enhanced their readiness to engage in pro-twin behavior.

In addition to identity fusion, a number of proximal causes of altruistic behaviour have been established so far, such as emotional closeness (Curry, Roberts, \& Dunbar, 2012; Korchmaros \& Kenny, 2001), empathy (de Waal, 2008), normative 
obligation (Gans \& Silverstein, 2006), and similarity (Rushton, 1998). Future studies should determine the relative influence of each mechanism and describe their interactions, if any.

Our findings also contribute to greater understanding of twin relationships and altruism. In Study 3, participants showed biologically significant preferences in that they were not more inclined to help their twin than their children. Given the high mean age of our participants (47-73 years), saving one's children would be biologically more advantageous than saving older relatives (e.g., parents or twins) whose reproductive period ended (see Wang, 1996). Nevertheless, consistent with evolutionary hypotheses (Hamilton, 1964), the willingness to prioritize the twin over one's children was more pronnounced in MZs as compared to DZs indicating that zygosity may significantly affect the hierarchy via identity fusion.

Whereas clear differences emerged between MZs and DZs in fusion and its correlates across three studies conducted with different samples and exploring various outcomes, differences among DZs were smaller and inconsistent. A meta-analysis of the three studies showed no differences in fusion between same-gender and differentgender DZs. Only in Study 1 different-gender DZs felt less fused with their twin than same-gender DZs and, consequently, expressed a weaker desire to have contact and coexperience with him/her. In Studies 2-3, however, fusion with the twin and willingness to forgive the twin and to prioritize him/her over other relatives were similar for both types of DZs. The outcome measures of Study 1 were related to the activities that twins make together, which are likely to be influenced by gender schemas (Bem, 1981). However, gender similarity was not as important when more costly behaviors were examined, for instance, when forgiving the twin or prioritizing him/her over other relatives. 
Finally some limitations should be noted. First, some results could be different if we had included younger pairs of twins. For intance, for participants of childbearing age helping a MZ twin -not a DZ- would be more biologically significant than helping one son/daughter (Wang, 1996). Second, to avoid fatigue some constructs were assessed by means only of one item. Third, for ethical reasons, our outcomes measures referred to hypothetical situations and behavioral intentions and we refrained from asking participants to choose between their twin and children (Korchmaros \& Kenny, 2001). Fourth, since all measures were assessed simultaneoulsy we cannot establish causality with great confidence. Nevertheless, based on previous research (Gómez \& Vázquez, 2015; Swann et al., 2012) the predicted path from fusion to behavioral intentions seems to be more plausible than the alternatives.

\section{Conclusion}

In three studies conducted with pairs of $\mathrm{MZ}$ and $\mathrm{DZ}$ twins we showed that identity fusion consistently mediated the effect of zygosity on the behavioral intentions towards one's twin. MZs were more fused with their twin than DZs and, in turn, they displayed elevations in desire for contact and coexperience with their twin, endorsements of forgiving the twin after an imagined disappointment and willingness to to make sacrifices for the twin compared to other relatives. These results suggest that identity fusion may be a key evolved mechanism of psychological kinship. 


\section{References}

Aron, E. N., \& Aron, A. (1996). Love and expansion of the self: The state of the model. Personal Relationships, 3(1), 45-58.

Aron, A., Aron, E. N., \& Smollan, D. (1992). Inclusion of Other in the Self Scale and the structure of interpersonal closeness. Journal of Personality and Social Psychology, 63(4), 596-612.

Bem, S. L. (1981). Gender schema theory: A cognitive account of sex typing. Psychological Review, 88(4), 354-364.

Buhrmester, M. D., Fraser, W. T., Lanman, J. A., Whitehouse, H., \& Swann Jr, W. B. (2015). When terror hits home: Identity fused Americans who saw Boston bombing victims as "family" provided aid. Self and Identity, 14(3), 253-270.

Curry, O., Roberts, S. G., \& Dunbar, R. I. (2013). Altruism in social networks: Evidence for a 'kinship premium'. British Journal of Psychology, 104(2), 283295.

Danby, S., \& Thorpe, K. (2006). Compatibility and conflict: Negotiation of relationships by dizygotic same-sex twin girls. Twin Research and Human Genetics, 9(01), 103-112.

De Waal, F. B. (2008). Putting the altruism back into altruism: The evolution of empathy. Annual Review of Psychology, 59, 279-300.

DeBruine, L. M. (2002). Facial resemblance enhances trust. Proceedings of the Royal Society of London B: Biological Sciences, 269(1498), 1307-1312.

Fortuna, K., Goldner, I., \& Knafo, A. (2010). Twin relationships: A comparison acoss monozygotic twins, dizygotic twins, and nontwin siblings in early childhood. Family Science, 1(3-4), 205-211. 
Gans, D., \& Silverstein, M. (2006). Norms of filial responsibility for aging parents across time and generations. Journal of Marriage and Family, 68(4), 961-976.

Gómez, A., Brooks, M. L., Buhrmester, M. D., Vázquez, A., Jetten, J., \& Swann Jr, W. B. (2011). On the nature of identity fusion: insights into the construct and a new measure. Journal of Personality and Social Psychology, 100(5), 918-933.

Gómez, Á., Morales, J. F., Hart, S., Vázquez, A., \& Swann, W. B. (2011). Rejected and excluded forevermore, but even more devoted: Irrevocable ostracism intensifies loyalty to the group among identity-fused persons. Personality and Social Psychology Bulletin, 37(12), 1574-1586.

Gómez, Á., \& Vázquez, A. (2015). The power of ‘feeling one’with a group: identity fusion and extreme pro-group behaviours. International Journal of Social Psychology, 30(3), 481-511.

Gould, W., \& Scribney, W. (1999). Maximum Likelihood Estimation with STATA. College Station, TX: Stata Press.

Hamilton, W. D. (1964). The genetical evolution of social behavior. Journal of Theoretical Biology, 7(1), 1-52.

Hayes, A. F. (2013). Introduction to mediation, moderation, and conditional process analysis: A regression-based approach. New York: Guilford Press.

Jong, J., Whitehouse, H., Kavanagh, C., \& Lane, J. (2015) Shared negative experiences lead to identity fusion via personal reflection. PLOS ONE 10(12): e0145611.

Joseph, J. (2013). The use of the classical twin method in the social and behavioral sciences: the fallacy continues. Journal of Mind and Behavior, 34(1), 1-39.

Korchmaros, J. D., \& Kenny, D. A. (2001). Emotional closeness as a mediator of the effect of genetic relatedness on altruism. Psychological Science, 12(3), 262-265. 
McGuire, S., Segal, N. L., Whitlow, B., Gill, P., \& Clausen, J. (2010). Sibling trust and trustworthiness. In K. Rotenberg (Ed.), Interpersonal trust during childhood and adolescence (pp. 133-154). Cambridge, England: Cambridge University Press.

Neyer, F. J. (2002). Twin relationships in old age: A developmental perspective. Journal of Social and Personal Relationships, 19(2), 155-177.

Ordoñana, J. R., Rebollo-Mesa, I., Carrillo, E., Colodro-Conde, L., García-Palomo, F. J., González-Javier, F., ... \& Pérez-Riquelme, F. (2013). The Murcia Twin Registry: a population-based registry of adult multiples in Spain. Twin Research and Human Genetics, 16(1), 302-306.

Rose, R. J. (2002). How do adolescents select their friends? A behavior-genetic perspective. In L. Pulikinnen \& A. Caspi (Eds.), Paths to successful development: Personality in the life course (pp. 106-125). New York: Cambridge University Press.

Rose, R. J., Kaprio, J., Williams, C. J., Viken, R., \& Obremski, K. (1990). Social contact and sibling similarity: Facts, issues, and red herrings. Behavior Genetics, 20(6), 763-778.

Rushton, J. P. (1998). Genetic similarity theory and the roots of ethnic conflict. The Journal of Social, Political, and Economic Studies, 23(4), 477-486.

Scarr, S., \& Carter-Saltzman, L. (1979). Twin method: defense of a critical assumption. Behavior Genetics 9(6), 527-542.

Segal, N. L. (2000). Virtual twins: New findings on within-family environmental influences on intelligence. Journal of Educational Psychology, 92(3), 442-448.

Segal, N. L., \& Hershberger, S. L. (1999). Cooperation and competition between twins: Findings from a prisoner's dilemma game. Evolution and Human Behavior, 20(1), 29-51. 
Segal, N. L., \& Ream, S. L. (1998). Decrease in grief intensity for deceased twin and non-twin relatives: An evolutionary perspective. Personality and Individual Differences, 25(2), 317-325.

Swann Jr, W. B., \& Buhrmester, M. (2015). Identity fusion. Current Directions in Psychological Science. 24(1), 52-57

Swann Jr, W. B, Buhrmester, M. D., Gómez, A., Jetten, J., Bastian, B., Vázquez, A., ... \& Zhang, A. (2014). What makes a group worth dying for? Identity fusion fosters feelings of familial ties, promoting self-sacrifice. Journal of Personality and Social Psychology, 106(6), 912-926.

Swann Jr, W. B., Gómez, Á., Buhrmester, M. D., López-Rodríguez, L., Jiménez, J., \& Vázquez, A. (2014). Contemplating the ultimate sacrifice: Identity fusion channels pro-group affect, cognition, and moral decision making. Journal of Personality and Social Psychology, 106(5), 713-727.

Swann Jr, W. B., Gómez, A., Seyle, D. C., Morales, J., \& Huici, C. (2009). Identity fusion: the interplay of personal and social identities in extreme group behavior. Journal of Personality and Social Psychology, 96(5), 995-1011.

Swann Jr, W. B., Gómez, Á., Vázquez, A., Guillamón, A., Segovia, S., \& Carrillo, B. (2015). Fusion with the cross-gender group predicts genital sex reassignment surgery. Archives of Sexual Behavior, 44(5), 1313-1318.

Swann Jr, W. B., Jetten, J., Gómez, A., Whitehouse, H., \& Bastian, B. (2012). When group membership gets personal: A theory of identity fusion. Psychological Review, 119(3), 441-456.

Vázquez, A., Gómez, Á., Ordoñana, J. R., \& Paredes, B. (2015). From interpersonal to extended fusion: relationships between fusion with siblings and fusion with the country. International Journal of Social Psychology, 30(3), 512-530. 
Thorpe, K., \& Gardner, K. (2006). Twins and their friendships: Differences between monozygotic, dizygotic same-sex and dizygotic mixed-sex pairs. Twin Research and Human Genetics, 9(01), 155-164.

Wang, X. T. (1996). Evolutionary hypotheses of risk-sensitive choice: Age differences and perspective change. Ethology and Sociobiology, 17(1), 1-15.

West, S. G., Aiken, L S., \& Krull, J.L. (1996). Experimental personality designs: Analyzing categorical by continuous variable interactions. Journal of Personality, 64(1), 1-48.

Whitehouse, H., McQuinn, B., Buhrmester, M., \& Swann, W. B. (2014). Brothers in arms: Libyan revolutionaries bond like family. Proceedings of the National Academy of Sciences, 111(50), 17783-17785.

Whitehouse, H., \& Lanman, J. A. (2014). The ties that bind us. Current Anthropology, 55(6), 674-695. 
Table 1. Composition of the samples

\begin{tabular}{llll} 
& $\begin{array}{l}\text { Study 1 } \\
(\mathrm{n}=190)\end{array}$ & $\begin{array}{l}\text { Study 2 } \\
(\mathrm{n}=482)\end{array}$ & $\begin{array}{l}\text { Study 3 } \\
(\mathrm{n}=226)\end{array}$ \\
\hline 1. MZs Males & 28 & 72 & 54 \\
2. MZs Females & 28 & 118 & 34 \\
3. DZs Males & 34 & 92 & 32 \\
& & & \\
4. DZs Females & 36 & 76 & 48 \\
& & & \\
5. DZs opposite-sex & 64 & 124 & 58 \\
\hline
\end{tabular}


Table 2. Study 1. Descriptive statistics and correlations

$\begin{array}{lllllllll}M & S D & 1 & 2 & 3 & 4 & 5 & 6 & 7\end{array}$

1. D1

2. D2

3. Gender

$\begin{array}{lllllll}\text { 4. Age } & 55.69 & 6.24 & .05 & -.05 & .01 & -\end{array}$

$\begin{array}{llllllll}\text { 5. Fusion } & 7.29 & 2.21 & -.20 * * & -.29 * * & .13 & .07 & -\end{array}$

6. Desire for

$\begin{array}{llllllll}3.69 & 1.44 & -.19 * & -.27 * * & .02 & -.11 & .45^{* *} & -\end{array}$

contact

7. Desire for coexperience

$$
\begin{array}{llllllll}
6.96 & 2.34 & -.15^{*} & -.17 * & -.01 & .03 & .60 * * & .44 * *
\end{array}
$$

Note: $* p<.05, * * p<.01$. 
Table 3. Study 1. Regression analyses.

\begin{tabular}{|c|c|c|c|c|c|c|c|c|c|c|c|c|}
\hline Predictors & \multicolumn{6}{|c|}{ Desire for contact with the twin } & \multicolumn{6}{|c|}{ Desire for coexperience } \\
\hline D1 (MZs vs. DZs) & $-0.62 * *$ & 0.29 & -.20 & -0.36 & 0.25 & -.12 & $-0.79 *$ & 0.38 & -.15 & -0.15 & 0.26 & -.03 \\
\hline Gender & 0.04 & 0.11 & .03 & -0.04 & 0.10 & -.02 & -0.03 & 0.16 & -.01 & -0.21 & 0.12 & -.09 \\
\hline Age & -0.03 & 0.02 & -.12 & -0.03 & 0.02 & -.13 & 0.01 & 0.03 & .03 & 0.00 & 0.02 & -.01 \\
\hline Fusion & & & & $0.26^{* * *}$ & 0.05 & 0.39 & & & & $0.64 * * *$ & 0.07 & .60 \\
\hline
\end{tabular}

Note: ${ }^{\mathrm{t}} p=.06,{ }^{*} p<.05, * * p<.01, * * * p<.001$. The standardized coefficients were not calculated with robust analyses. 
Table 4. Study 2. Descriptive statistics and correlations

\begin{tabular}{lllllllllllll}
$M$ & $S D$ & 1 & 2 & 3 & 4 & 5 & 6 & 7 & 8 \\
\hline
\end{tabular}

\section{D1}

2. D2

3. Gender

4. Age

$\begin{array}{lllll}55.78 & 6.76 & .13^{* *} & .15^{* *} & -.02\end{array}$

5. Disappointment

$\begin{array}{llll}-.05 & .03 \quad .00 \quad-\end{array}$

6. Fusion

$\begin{array}{lll}7.15 & 2.12 & -.28 * *\end{array}$

7. Another chance

8. Favor

$9.38 \quad 1.36 \quad-.11 *$


Table 5. Study 2. Regression analysis on willigness to trust the twin again.

\begin{tabular}{|c|c|c|c|c|c|c|c|c|c|}
\hline \multirow[b]{2}{*}{ Predictors } & \multicolumn{3}{|c|}{ Model 1} & \multicolumn{3}{|c|}{ Model 2} & \multicolumn{3}{|c|}{ Model 3} \\
\hline & $B$ & $S E B$ & $\beta$ & $B$ & $S E B$ & $\beta$ & $B$ & $S E B$ & $\beta$ \\
\hline D1 & $-0.26^{*}$ & 0.12 & -.09 & $-0.46^{*}$ & 0.18 & -.17 & -0.28 & 0.17 & -.10 \\
\hline D2 & 0.14 & 0.20 & .04 & -0.06 & 0.33 & -.02 & 0.00 & 0.32 & .00 \\
\hline Gender & $-0.15^{*}$ & 0.06 & -.11 & $-0.15^{*}$ & 0.06 & -.11 & $-0.15 * *$ & 0.06 & -.11 \\
\hline Age & -0.01 & 0.01 & -.03 & 0.00 & 0.01 & -.02 & -0.01 & 0.01 & -.03 \\
\hline Disappointment & & & & $-0.38 * *$ & 0.12 & -.25 & $-0.30 * *$ & 0.11 & -.20 \\
\hline D1*Disappointment & & & & $-0.39 *$ & 0.19 & -.14 & $-0.35^{\mathrm{t}}$ & 0.19 & -.13 \\
\hline D2*Disappointment & & & & -0.28 & 0.35 & -.08 & -.0 .22 & 0.34 & -.07 \\
\hline Fusion & & & & & & & $0.12 * * *$ & 0.03 & 0.19 \\
\hline$R^{2}$ & .03 & & & .09 & & & .13 & & \\
\hline$F$ for change in $R^{2}$ & $3.29 *$ & & & $3.70^{* * * *}$ & & & $4.43 * * *$ & & \\
\hline
\end{tabular}

Note: ${ }^{\mathrm{t}} p=.06,{ }^{*} p<.05,{ }^{* *} p<.01, * * * \mathrm{p}<.001$. The standardized coefficients were not calculated with robust analyses. 
Table 6. Study 2. Regression analysis on willigness to do the twin a favor.

\begin{tabular}{|c|c|c|c|c|c|c|c|c|c|}
\hline \multirow[b]{2}{*}{ Predictors } & \multicolumn{3}{|c|}{ Model 1} & \multicolumn{3}{|c|}{ Model 2} & \multicolumn{3}{|c|}{ Model 3} \\
\hline & $B$ & $S E B$ & $\beta$ & $B$ & $S E B$ & $\beta$ & $B$ & $S E B$ & $\beta$ \\
\hline D1 & $-0.27 *$ & 0.13 & -.10 & $-0.41^{*}$ & 0.18 & -.15 & -0.20 & 0.19 & -.07 \\
\hline D2 & -0.02 & 0.18 & -.01 & -0.28 & 0.28 & -.08 & -0.22 & 0.28 & -.06 \\
\hline Gender & -0.07 & 0.06 & -.05 & -0.07 & 0.06 & -.05 & -0.07 & 0.06 & -.05 \\
\hline Age & 0.00 & 0.01 & .01 & 0.00 & 0.01 & .02 & 0.00 & 0.01 & .01 \\
\hline Disappointment & & & & $-0.29 * *$ & 0.11 & -.19 & $-0.21^{t}$ & 0.11 & -.14 \\
\hline D1*Disappointment & & & & -0.26 & 0.18 & -.09 & -0.21 & 0.18 & -.08 \\
\hline $\mathrm{D} 2 *$ Disappointment & & & & -0.43 & 0.30 & -.13 & -0.34 & 0.30 & -.10 \\
\hline Fusion & & & & & & & $0.15^{* * *}$ & 0.04 & 0.24 \\
\hline$R^{2}$ & .01 & & & .06 & & & .10 & & \\
\hline$F$ for change in $R^{2}$ & $2.88^{*}$ & & & $2.80^{* *}$ & & & $4.13^{* * *}$ & & \\
\hline
\end{tabular}

Note: ${ }^{\mathrm{t}} p=.05,{ }^{*} p<.05, * * p<.01, * * * p<.001$. The standardized coefficients were not calculated with robust analyses. 
Table 7. Study 3. Descriptive statistics and correlations

$\begin{array}{lllllllll}M & S D & 1 & 2 & 3 & 4 & 5 & 6 & 7\end{array}$

1. D1

2. D2

3. Gender

4. Age

$\begin{array}{lllll}55.30 & 6.37 \quad .15 * & -.04 & .05\end{array}$

5. Fusion

$\begin{array}{lllll}6.97 & 2.36 & -.20 * * & .06 & -.02\end{array}$

.03

6. Pro-parents

intentions

$5.42 \quad 2.71$

7. Pro-children

intentions

$\begin{array}{llllllll}3.31 & 2.73 & -.16 * & .03 & -.01 & -.05 & .39 * * & .56 * *\end{array}$

Note: $* p<.05, * * p<.01$ 
Table 8. Study 3. Regression analyses.

\begin{tabular}{|c|c|c|c|c|c|c|c|c|c|c|c|c|}
\hline Predictors & \multicolumn{6}{|c|}{ Prioritizing the twin over one's parents } & \multicolumn{6}{|c|}{ Prioritizing the twin over one's children } \\
\hline D1 & $-1.13^{*}$ & 0.46 & -.20 & -0.57 & 0.42 & -.10 & $-0.90 *$ & 0.44 & -.16 & -0.47 & 0.40 & -.08 \\
\hline Gender & -0.29 & 0.22 & -.11 & -0.15 & 0.18 & -.05 & -0.09 & 0.20 & -.03 & -0.04 & 0.18 & -.01 \\
\hline Age & 0.01 & 0.04 & .01 & 0.00 & 0.03 & .01 & -0.01 & 0.03 & -.02 & -0.02 & 0.03 & -.05 \\
\hline Fusion & & & & $0.60 * * *$ & 0.09 & .54 & & & & $0.43^{* * *}$ & 0.07 & .37 \\
\hline
\end{tabular}

Note: $* p<.05, * * p<.01, * * * p<.001$. The standardized coefficients were not calculated with robust analyses. 
Figure captions

Figure 1. Study 1. Indirect effects via fusion on desire for contact with the twin.

Figure 2. Study 1. Indirect effects via fusion on desire for coexperience with the twin. Figure 3. Study 2. Indirect effect via fusion on willingness to trust the twin.

Figure 4. Study 2. Indirect effect via fusion on willingness to do the twin a favor.

Figure 5. Study 3. Indirect effect via fusion on willingness to prioritize the twin over parents.

Figure 6. Study 3. Indirect effect via fusion on willingness to prioritize the twin over children. 